\title{
Tramas históricas a respeito da psiquiatrização, disciplina e medicalização em algumas lentes de Michel Foucault ${ }^{1}$
}

\section{Historical plots about psychiatry, discipline and medicalization in some of Michel Foucault's lenses}

\author{
FLÁVIA CRISTINA SILVEIRA LEMOS \\ Professora associada III de Psicologia Social- \\ Universidade Federal do Pará/UFPA - Brasil \\ flaviacslemos@gmail.com \\ BRUNO JÁY MERCÊS DE LIMA \\ Professor substituto de Enfermagem. \\ Universidade Estadual do Pará -UEPA \\ bruno_lima@hotmail.com \\ DIEGO HENRIQUE DA SILVA TRUJILLO \\ Psicólogo no Sistema Único de Saúde \\ diegostrujillo@gmail.com \\ ADIVAN JARBAS MOREIRA SOARES \\ Mestre em Psicologia - Universidade Federal do Maranhão/UFMA \\ adivansoares@hotmail.com \\ THIAGO DA SILVA PINHEIRO \\ Mestre em Psicologia - Universidade Federal do Pará/UFPA \\ pinheiro@ hotmail.com \\ LEANDRO PASSARINHO REIS JÚNIOR \\ Professor adjunto IV de Psicologia do Educação. \\ Universidade Federal do Pará/UFPA \\ lpassarinho23@gmail.com
}

\section{RESUMO}

Este artigo busca traçar em formato de ensaio teórico uma trama histórica de alguns operadores analíticos dos procedimentos de psiquiatrização da sociedade e da medicalização dos corpos por meio de práticas sociais normalizadoras e disciplinares. Pensar estes acontecimentos e como são interrogados e trabalhados por Michel Foucault é uma proposta importante e nos auxilia a fazer perguntas a respeito do presente na medida em que diversas análises permitem correlações com a atualidade vivida e, assim, possibilita problematizar a considerável força da psiquiatria social hoje, reconfigurando as políticas de saúde mental disciplinadoras por um viés medicalizante e normalizador cada vez mais intenso em nome da defesa da sociedade. Logo, o presente texto contribui para diversas áreas de modo transdisciplinar no trabalho atento de desnaturalização histórica dos processos de medicalização e psiquiatrização da vida como norma disciplinar e social.

Palavras-chave: História da psiquiatrização. Medicalização. Sociedade. Disciplina. Norma.

\footnotetext{
${ }^{1}$ Artigo submetido para avaliação em 25 de agosto de 2021 e aprovado em 12 de novembro em 2021.
} 
Rev. Interd. em Cult. e Soc. (RICS), São Luís, v. 7, n. 2, p. 261- 275, jul./dez. 2021

ISSN eletrônico: $2447-6498$

\begin{abstract}
This article seeks to trace, in a theoretical essay format, a historial plots of some analytical operators of the psychiatric procedures of society and the medicalization of bodies through normalizing and disciplinary social practices. Thinking about these events and how they are interrogated and worked on by Michel Foucault is an important proposal and helps us to ask questions about the present, as several analyzes allow correlations with the current experience and, thus, make it possible to problematize the considerable strength of social psychiatry. today, reconfiguring disciplinary mental health policies through an increasingly intense medicalizing and normalizing bias in the name of defending society. Therefore, this text contributes to several areas in a transdisciplinary way in the careful work of historical denaturalization of the processes of medicalization and psychiatrization of life as a social and disciplinary norm.
\end{abstract}

Keywords: History of psychiatrization. Medicalization. Society. Subject. Standard.

\title{
INTRODUÇÃO
}

Este artigo visa pensar por meio de uma história do panorama de algumas práticas de psiquiatrização da sociedade e alguns de seus efeitos destas nas práticas de produção da subjetividade, a partir de uma perspectiva dos estudos históricos de Michel Foucault. Busca-se problematizar os processos e mecanismos que operaram um programa de normalização por meio da medicalização na gestão da vida pela disciplina dos corpos.

Trata-se de um ensaio teórico, a partir de uma analítica baseada em Michel Foucault sobre alguns operadores do poder disciplinar na normalização da sociedade a partir da psiquiatrização como defesa social, nos últimos séculos, em um breve percurso problematizador das práticas medicalizantes. Trata-se de um texto pautado em uma metodologia histórico-social, baseada em trabalhos da Nova História Cultural em conversação com a Arqueogenealogia, no período histórico dos séculos XVII ao XX, na perspectiva de um recorte da História Contemporânea.

\section{HISTÓRIA DA DISCIPLINA E NORMALIDADE NA PSIQUIATRIZAÇÃO SOCIAL}

Neste tópico, aborda-se a relação entre a psiquiatrização da vida pela normalização social no que tange o poder disciplinar em interface com a esfera da lei, no campo da soberania jurídica da construção do Estado Moderno. A vertente legal e jurídica era e ainda é relevante para regular a sociedade e as condutas, todavia, não teria 
Rev. Interd. em Cult. e Soc. (RICS), São Luís, v. 7, n. 2, p. 261- 275, jul./dez. 2021

ISSN eletrônico: 2447-6498

a mesma agilidade e generalização e até mesmo a capacidade preventiva das práticas disciplinares na dimensão parajudiciária, adjacente à ordem jurídica e às organizações do Poder Judiciário. As psicopatologias e os efeitos destas podem escapar de várias formas aos mecanismos judiciais de defesa social. Portanto, era necessário, gerir as existências antes de um crime e fora da condição de uma doença já instalada, também.

O que seria um comportamento ameaçador e construtor de uma suposta personalidade violenta e criminosa passaria a ser um objeto de preocupação de juristas, médicos, educadores e gestores quando estavam diante de situações que não conseguiam explicar ou justificar socialmente, dada a dimensão de impacto e espanto cultural e político. Em especial, quando se tratava de atitudes e modos de viver díspares dos modelos instituídos em uma certa realidade histórico-cultural.

Médicos e juristas passaram a buscar elementos que denominaram de circunstâncias atenuantes aos crimes e desenvolvimento de psicopatologias considerados graves e que seriam perigosos para a sociedade, na lógica de um Estado organizado pela ordem e lei liberal e capitalista. Foucault (2002) descreveu e analisou estes acontecimentos, delimitando as emergências de novos saberes e objetos assessores e adjacentes à racionalidade do Estado de disciplinar e gerir a sociedade tanto na minúcia quanto nos segmentos amplos de governo. Entre estes saberes e poderes, é possível destacar: Medicina preventiva, Psiquiatria social e comunitária, Neurologia aplicada à educação e justiça, Psicologia Jurídica e da Saúde, Pedagogia, Direito, Economia Política e Estatística (FOUCAULT, 2012).

A sociedade disciplinar opera práticas de saber e poder referentes ao quadro de atendimento médico-psicológico tendo em vista parâmetros disciplinares de governo das condutas quanto ao estímulo ao desempenho expandido com qualidade, no que tange ao ajustamento das condutas, na dimensão da regularidade mínima da produtividade, no plano da docilização política por meio da obediência às regras sociais e culturais e, também nas avaliações e vigilâncias quanto à adequação dos comportamentos às normas e modelos de se conduzir, em uma determinada sociedade.

As táticas disciplinares visavam avaliar o desempenho por meio dos exames permanentes das práticas realizadas face aos modelos esperados; controlar o tempo de cada atividade realizada conforme ideais de produção; regular os corpos no espaço, colocando cada corpo em um espaço específico; sancionar as condutas consideradas 
Rev. Interd. em Cult. e Soc. (RICS), São Luís, v. 7, n. 2, p. 261- 275, jul./dez. 2021

ISSN eletrônico: $2447-6498$

anormais e de desobediência e, por fim, vigiar hierarquicamente as existências e organizar os corpos de acordo com os modos previstos de condução da subjetividade.

No curso O Poder Psiquiátrico (2012), ministrado no Collège de France entre 1973-1974, Foucault versa sobre a questão de todo um aparato disciplinar que se relacionou com o estabelecimento do saber médico, e que os primeiros tratados acerca das práticas psiquiátricas demonstram que nos espaços asilares as prescrições de tratamento dos loucos apontavam mais sobre estratégias disciplinares do que sobre um campo de saber constituído da loucura sobre o qual se deveria seguir. O filósofo destaca o texto prescritivo sobre o tratamento das doenças mentais, de um dos precursores da psiquiatria, no qual ele atribuía à questão do porte do médico perante o espaço psiquiátrico e aos internos, um dos principais meios pelo qual se poderia enfrentar a loucura, isto é, o médico deveria se portar de forma que impusesse respeito, confiança, assimetria na relação com o internado, visto que neste período a loucura era entendida como um excedente de instintos, paixões, forças com as quais o louco utilizava para poder configurar a noção de sua suposta enfermidade mental.

No espaço asilar não só a presença física com seus efeitos disciplinares era importante para o tratamento, mas também os outros funcionários, tais como serventes, vigilantes, pois como estes passavam mais tempo em contato com os loucos, eles não só informavam tudo o que se passava com os internos ao médico, mas como também reforçavam a figura do médico como aquele que poderia realmente ajudar na cura da loucura, pelo fato de que eles conviviam muito mais com os asilados do que o psiquiatra. Enfim, todo um jogo de táticas era desenvolvido dentro do espaço asilar para formar um campo de enfrentamento entre o médico com sua imponência e o louco com a sua enfermidade mental. A questão que estava posta dizia respeito aos procedimentos de caráter disciplinar, tais quais: a vigilância, a subjugação, as informações obtidas, os funcionários funcionando como olhos e ouvidos do médico, para que a loucura fosse interpelada de maneira que o doente fosse coagido e obrigado a aceitar a sua condição e consequentemente se libertasse de sua loucura (FOUCAULT, 2006).

No século XIX, período em que a psiquiatria vai sendo desenvolvida com suas prescrições, técnicas e táticas para o enfrentamento da loucura, é também o período em que os sistemas disciplinares já se encontram num estágio de dispersão e expansão cada vez maiores sobre o corpo social. O que se podia observar nas escolas, nos hospitais, nas prisões, em instituições para; judiciárias etc. Portanto, normas de comportamento, 
Rev. Interd. em Cult. e Soc. (RICS), São Luís, v. 7, n. 2, p. 261- 275, jul./dez. 2021

ISSN eletrônico: 2447-6498

de controle e de saber acerca das virtualidades do psiquismo já eram formuladas, e os sistemas disciplinares através de suas redes já direcionavam discursos de verdade sobre a relação entre o assujeitamento disciplinar e determinada apreciação de normalidade.

Foucault ao dizer que os sistemas disciplinares que classificam, hierarquizam, vigiam, vão esbarrar naqueles que não podem ser classificados, naqueles que escapam da vigilância, os que não podem entrar no sistema de distribuição, isto é, naqueles que serão considerados o resíduo, o irredutível, o inclassificável, o inassimilável, o ponto limite do poder disciplinar. Por exemplo, a figura do débil mental era aquela que se tornava um ponto limite da disciplinar escolar, a figura do delinquente era um ponto limite da disciplina policial, e dentre estas figurais residuais aquele que será considerado o mais residual de todos será o doente mental. (FOUCAULT, 2012).

A função do sistema disciplinar de garantir a fixação dos indivíduos em um fenômeno de refamiliarização no ponto de articulação entre soberania e disciplina. O louco, por sua vez, resíduo em seu grau máximo, torna-se o inimigo da célula familiar e de toda a sociedade. Por conseguinte, não só o internamento do louco nos asilos como todas as funções psiquiátricas, relacionadas com a normalização se tornam possíveis.

Desta maneira empreende-se a noção de que o louco ou o anormal em relação à família, representação de soberania na sociedade disciplinar, tem de ser corrigido, normalizado por outras instâncias que vão implementar ações, estratégias, terapêuticas para que ele seja devolvido à família não mais representando perigo. Decorre-se também destas questões a ideia de que a internação e os aparelhos corretivos se tornam necessários, pois é preciso um afastamento da família, a qual pode influenciar negativamente no tratamento. Além de que entre 1850-1860 aparece uma ideia de que o louco se comporta como se fosse uma criança, portanto deve ser colocado num espaço em que funcione como uma espécie de família ortopédica que vai permitir a sua reinserção na família de origem.

Portanto, como Foucault (2012) aponta, a criança vai se tornar o alvo principal da intervenção psiquiátrica. É como se a psiquiatria dissesse que nunca se é jovem demais para ser louco. Observa-se então, através da noção de que o louco assim o é por questões familiares, que a loucura se inscreve em estágios anteriores da formação do indivíduo. É preciso vigiar a família, é preciso atentar-se para que a criança não venha desenvolver patologias no futuro. $\mathrm{O}$ internamento $\mathrm{e}$ as instituições corretivas garantem a defesa de uma possibilidade de anormalidade que pode estar presente, mesmo que 
Rev. Interd. em Cult. e Soc. (RICS), São Luís, v. 7, n. 2, p. 261- 275, jul./dez. 2021

ISSN eletrônico: 2447-6498

sutilmente, em todas as pessoas. É inclusive, para Foucault (2012), que a partir da infância que a psiquiatria vai se difundir pela sociedade. Houve, portanto uma psiquiatrização da infância.

"Foi por intermédio da criança não louca que se fez a psiquiatrização da criança e, a partir daí, que se produziu essa generalização do poder psiquiátrico." (FOUCAULT, 2012, p.257). Daí se constroem noções, por exemplo, sobre a idiotia, que é a condição em que as qualidades intelectuais não se desenvolvem, condição portanto distinta da loucura. Definição que estabelece as condições para o surgimento da psicologia do desenvolvimento (FOUCAULT, 2012).

Observa-se pela difusão das práticas psiquiátricas na sociedade que os conceitos de normalidade e anormalidade vão se afirmando como regras de conduta e de apreciação de verdade em distintas e variadas instituições. Diante de todos estes acontecimentos e desdobramentos que envolvem técnicas disciplinares terapêuticas, defesa da família, proteção da infância, o psiquiatra vai se tornar aquele que pode dizer sobre a realidade e, portanto, pode mediante suas técnicas direcionar a realidade àqueles que dela se desviam. O psiquiatra, ao assumir a função de "direção" do espaço asilar, procura direcionar a consciência dos que estão submetidos sob seu poder através de uma manipulação da realidade com fins coativos. E, para tanto, utilizará de determinados mecanismos suplementares de realidade. Observa-se então toda uma disposição estratégica dos espaços e de cenários na prática asilar como forma de fazer penetrar a realidade no corpo do louco.

Este jogo de realidade, organizado no espaço asilar pelo psiquiatra com finalidades terapêuticas consistirá em alguns elementos, dentre os quais, em primeiro lugar, era necessário que nesta tensão de forças entre o médico e o louco, o primeiro detivesse um poder superior ao do segundo. Ao psiquiatra também cabia realizar uma anamnese, uma pesquisa biográfica do louco de forma que este pudesse, através de um ritual próximo ao da confissão, reconhecer quem ele era de fato. Cabia ao psiquiatra também mediante um jogo de provas da realidade, fazer com o que o louco reconhecesse o seu desejo pela sua loucura, e esta questão era enfrentada utilizando-se de intervenções morais para despertar no louco o mau que havia se apoderado dele. E por fim, questões relativas ao trabalho eram levantadas, já que no espaço asilar estimulava-se o processo de trocas e de utilidades dentro de um sistema cuja principal 
Rev. Interd. em Cult. e Soc. (RICS), São Luís, v. 7, n. 2, p. 261- 275, jul./dez. 2021

ISSN eletrônico: $2447-6498$

função era a de reativar o processo de realidade referente às necessidades que se podem ser atendidas com o dinheiro, com o trabalho.

No curso referido, Foucault ressalta que ainda no século XVIII os espaços asilares não eram necessariamente espaços médicos, pois tais espaços eram coordenados especialmente por religiosos, entretanto, a partir do século XIX, a presença do médico, que num primeiro momento atendia a funções de um médico comum que cuidava do bem-estar dos doentes, passou a ser fundamental na direção, pois além das técnicas disciplinares que passou a conduzir dentro do espaço asilar, uma questão era fundamental para garantir o sucesso do tratamento: a presença física do médico.

A tese sustentada por Foucault é de que no começo do século XIX a presença física do médico se tornou fundamental nos espaços asilares (mesmo de que não dispusesse de um saber organizado em torno de nosografias e localizações orgânicas sobre as doenças mentais), porque fazendo funcionar mecanismos disciplinares no interior do espaço asilar, ele próprio se tornava um agente de direcionamento da realidade na medida em que ele próprio se tornava o asilo, isto é, o asilo tornara-se o corpo do psiquiatra.

Além do mais, Foucault corrobora sua tese de que a inserção do médico no espaço asilar não foi decorrente de um anterior saber terapêutico para a loucura, pois o processo terapêutico consistia no que o filósofo chamou de "marcas de saber" sobre o espaço asilar, as quais consistiam num interrogatório, que mais do que extrair informações sobre o doente, visavam fazer com que louco acreditasse que o médico soubesse de tudo o que se passava com ele, até porque a outros funcionários do estabelecimento era cabida a função de construir registros e dossiês sobre os internos.

Além de punições que muitas vezes o psiquiatra aplicava ao louco, aos quais, este tinha que compreendê-las como se fossem um remédio. A outra marca de saber refere-se à prática da apresentação clínica do louco perante outros estudantes. Prática esta na qual os estudantes assistiam o louco sendo interrogado para que este possa apreender o efeito de poder da palavra do médico sendo multiplicado pela presença dos ouvintes. É como se na presença dos estudantes o médico mostrasse que sabia da verdade do louco. Estas marcas de saber das quais a psiquiatria até este momento fazia funcionar encontraram, todavia, um entrave. Ainda no século XIX se dá o aparecimento da neurologia, mais especificamente da neuropatologia, que através de alguns estudos e experimentações permitiu realizar correlações entre lesões orgânicas e 
Rev. Interd. em Cult. e Soc. (RICS), São Luís, v. 7, n. 2, p. 261- 275, jul./dez. 2021

ISSN eletrônico: $2447-6498$

uma série de distúrbios cuja sede neurológica e cuja etiologia neuropatológicas podiam ser efetivamente determinadas. O aparecimento deste novo campo de saber colocava o problema da seriedade, da autenticidade da doença mental; o que começava a fazer correr a suspeita de que, afinal de contas, uma doença mental que não tivesse correlação anatômica devia mesmo ser considerada séria? (FOUCAULT, 2012).

Diante deste impasse que a neurologia formulou para a psiquiatria é que esta passou a se introduzir em outros campos. Foi mencionada a questão da difusão da psiquiatria pela via da infância, porém cabe explanar também outras noções que surgiram a partir desta amplificação do poder psiquiátrico por tal caminho (FOUCAULT, 2012, p.279).

A psiquiatria afirma-se cada vez mais seu discurso referentes às problemáticas que podem existir dentro de um espectro de mal desenvolvimento, o qual é capaz de gerar não só atrasos, dificuldades, mas também a propensão, a maior probabilidade de que o indivíduo, principalmente por ter um histórico, marcas, restos de loucura dos pais, seja um degenerado, um anômalo, um anormal, portanto um perigo. À psiquiatria caberia então inclusive o papel de responder se o indivíduo que cometera algum crime apresentara sinais de doença mental. Esta aproximação com o discurso da criminologia não só expandiu as apreciações de normalidade para o campo das penalidades, mas como garantia que o campo das anormalidades e da loucura fosse garantido. Uma noção é importante de destacar na medicina clássica, a noção de "crise".

Ela se refere ao momento em que a doença era compreendida através de um olhar médico atento que observa seu desenvolvimento, seu curso natural, encontra-se em um ponto crítico de erupção, a partir da qual o médico que acompanha o doente, vigia, observa, coloca em ação uma terapêutica que se baseava na luta, no enfrentamento de forças que se materializavam no corpo do enfermo. Todavia na medicina em geral, na Europa do século XVIII, começa a se edificar um equipamento hospitalar e médico, que permitia a vigilância geral das populações, possibilitando estender o princípio de inquérito a todos os indivíduos, de maneira que a doença poderia ser controlada, isolada, estudada. A doença então compreendida por um outro olhar, um olhar analítico que permitia o estudo da doença em sua verdade, tais quais suas formas de contágio, através da projeção da doença no corpo morto e dos estudos sobre anatomia patológica, reverberaram no esmaecimento da noção de crise neste campo de saber. 
Rev. Interd. em Cult. e Soc. (RICS), São Luís, v. 7, n. 2, p. 261- 275, jul./dez. 2021

ISSN eletrônico: 2447-6498

\section{PSIQUIATRIZAÇÃO E MEDICALIZAÇÃO DO ESPAÇO}

$\mathrm{Na}$ psiquiatria, a situação ocorria de maneira distinta da medicina geral. Enquanto nesta, a noção de crise foi superada, devido todo um aparato médicohospitalar e técnicas de esquadrinhamento que possibilitaram o conhecimento, controle e prevenção dos contágios, no campo psiquiátrico a noção de "crise" persistiu e além do mais possuía um contorno de caráter estratégico. Como ao psiquiatra, no primeiro momento em que o saber psiquiátrico estabelecia seu domínio, não era imprescindível que ele procede uma classificação nosológica de doenças pela forma de investigação do inquérito (como na medicina geral). Sua principal função era a de estabelecer não um diagnóstico diferencial, senão um diagnóstico absoluto. Tratava-se então de dizer se o indivíduo era louco ou não, se o indivíduo estava ou não estava dentro do domínio da realidade (FOUCAULT, 2012).

É justamente nesta posição de arbitragem da realidade que a noção de crise se atualizará na psiquiatria de uma forma distinta que era encontrada na medicina geral. A noção de crise desta última estava relacionada com a prova da verdade, a qual consistia no embate de forças entre o corpo do doente e a própria doença. Já na psiquiatria o embate da prova significará uma prova de realidade. Foucault nomeia de duplicação administrativo-médica a prova psiquiátrica, pois ao psiquiatra cabe o questionamento de se atender uma demanda que possa ser transcrita em termos de sintomas e em termos de doença.

“Trata-se de fazer existir como doença ou eventualmente como não-doença os motivos dados para um internamento ou uma intervenção-psiquiátrica possível”. O que coloca o psiquiatra em uma posição pelo qual é responsável tanto por administrar a demanda que chega até ele, como ao mesmo tempo ele é a figura responsável pela aplicação dos procedimentos disciplinares que permeiam sua prática.

No livro Vigiar e Punir (2014) Foucault descreve o policiamento espacial que se efetuou em uma cidade infestada pela peste no século XVII. A fim de evitar o contágio da doença, os habitantes são trancados em suas casas pelos próprios síndicos. Sua alimentação é controlada e administrada por representantes do governo. As pessoas são, portanto, proibidas de circularem pela cidade, e caso desobedeçam, correm o risco de serem infectadas pela peste ou de serem punidas com a pena de morte. Vigilantes são 
Rev. Interd. em Cult. e Soc. (RICS), São Luís, v. 7, n. 2, p. 261- 275, jul./dez. 2021

ISSN eletrônico: $2447-6498$

designados para inspecionar ruas, quarteirões, bairros. Diariamente o síndico visita as casas pelas quais são responsáveis para verificar a situação dos moradores, se escondem doentes ou mortos. Tal vigilância se baseia em registros, relatórios organizados pelos síndicos com nomes dos moradores, idade, sexo, e que depois são entregues aos intendentes e destes, ao prefeito.

Os relatórios que são produzidos são entregues a médicos responsáveis pela administração das irregularidades para fins de controle. Os procedimentos médicos só serão adotados a partir do que é verificado e relatado. "O registro do patológico deve ser constante e centralizado. A relação de cada um com sua doença e sua morte passa pelas instâncias de poder, pelo registro que delas é feito, pelas decisões que elas tomam”. (FOUCAULT, 2014, p.191). Diferente de uma distribuição de corpos suscitada pela lepra que consistia em modelos de exclusão, com sua divisão maciça e binária entre uns e outros, a peste suscitava modelos disciplinares, porque recorria a separações múltiplas, a distribuições individualizantes, a uma organização aprofundada das vigilâncias e dos controles e a uma intensificação e ramificação do poder.

São, portanto, dois modelos distintos que envolvem duas maneiras de exercer poder sobre os homens, de controlar suas relações, de desmanchar suas perigosas misturas. Toda a hierarquia, vigilância, o olhar, a documentação de uma cidade infestada pela peste parece ser a utopia de uma cidade perfeitamente governada, pois funciona através de um poder extensivo que age de maneira diversa sobre todos os corpos individuais.

Foucault (2014) sustenta ainda que embora os modelos sejam diferentes, não são, entretanto, incompatíveis, visto que no século XIX (período em que o poder disciplinar se difunde por toda a sociedade), o processo de exclusão aplicado aos leprosos, vai sendo aplicado também a determinadas categorias sociais indesejáveis, tais como: mendigos, vagabundos, loucos. Ocorre o que o filósofo chamou de tratar os "leprosos" como "pestilentos", pois o processo de exclusão que se aplicará sobre eles é decorrente de processos de individualização, os quais são possibilitados pelos métodos de repartição analítica do poder: a individualização dos excluídos.

Este processo de exclusão pela individualização, possibilitado por um poder disciplinar que vigia, separa, constrói relatórios, vai ser aplicado em determinados lugares, espaços, como: o asilo psiquiátrico, a penitenciária, a casa de correção, o estabelecimento da educação vigiada. No caso dos hospitais, Foucault diz que de um 
Rev. Interd. em Cult. e Soc. (RICS), São Luís, v. 7, n. 2, p. 261- 275, jul./dez. 2021

ISSN eletrônico: $2447-6498$

modo geral todas as instâncias de controle individual funcionam de um duplo modo: o da divisão binária e da marcação (louco-não louco; perigoso-inofensivo; normalanormal), e de uma determinação coercitiva, da repetição diferencial (quem é ele; onde deve estar; como caracterizá-lo, como reconhecê-lo, como exercer sobre ele, de maneira individual, uma vigilância constante etc.). (FOUCAULT, 2014, p.193). O que ocorre então é uma espécie de "pestilentalização" do leproso, visto que há uma imposição aos excluídos de táticas das disciplinas individualizantes. A tentativa de universalizar os controles disciplinares permite marcar quem é "leproso" e fazer funcionar contra ele os mecanismos dualistas da exclusão. Surgem técnicas e instituições que assumem a tarefa de corrigir e controlar os anormais, fazendo funcionar os dispositivos disciplinares que foram observados na gestão da cidade empestada.

Este processo de individualização na exclusão, de quadriculamento do espaço por um viés medicalizante também pode ser encontrado em A Política da Saúde no Século XVIII (1979h) de Foucault, quando o filósofo aborda a relação estratégica entre uma medicina privada e uma medicina socializada, ao qual ele chamou de noso-política, isto é, a emergência de discursos, ações, políticas de gestão dos corpos, das populações, das circulações, dos espaços com vias de garantir e promover a saúde, evitar e combater as doenças e os contágios.

Neste texto, Foucault diz que a noso-política aparece no século XVIII como um "problema de origens e direções múltiplas: a saúde de todos como urgência para todos; o estado de saúde de uma população como objetivo geral." Ele demarca a separação entre ações assistenciais direcionadas aos pobres que se realizavam até o século XVII, tais quais as doenças que acompanhavam estes grupos, para uma preocupação com a mão-de-obra proveniente das camadas empobrecidas da população, que começavam a configurar uma problemática do ponto de vista do aparelho produtivo e da expansão demográfica.

É a questão do ócio-útil, e relacionado a isto, o surgimento da saúde e do bemestar físico da população em geral como um dos objetivos do poder político. Portanto, maneiras de se elevar o nível de saúde do corpo social em conjunto. "Os diversos aparelhos de poder devem se encarregar dos "corpos" não simplesmente para exigir deles o serviço do sangue ou para protegê-los contra os inimigos, não simplesmente para assegurar os castigos ou extorquir as rendas, mas para ajudá-los a garantir sua saúde. O imperativo da saúde: dever de cada um e objetivo geral.” (FOUCAULT, 
Rev. Interd. em Cult. e Soc. (RICS), São Luís, v. 7, n. 2, p. 261- 275, jul./dez. 2021

ISSN eletrônico: $2447-6498$

1979h, p. 109). Garantia da saúde que começa a se engendrar por ações médicodisciplinares com contornos produtivo-utilitaristas.

O filósofo destaca ainda que a importância que a medicina obtém no século XVIII tem origem no ponto de origem no cruzamento de uma nova economia "analítica" da assistência com a emergência de uma "polícia" geral da saúde. Entra em cena uma polícia do corpo social, que cumpre objetivos político-econômicos fundamentais na sociedade industrial que vai se desenvolvendo.

Tal polícia de saúde, que inclusive terá como um dos alvos principais a família, em especial a criança, privilegiará questões relacionadas à higiene, fazendo a medicina funcionar como uma instância de controle social. E a noção de "regime", que antes dizia respeito a uma regra do modo de vida e de uma medicina preventiva vai sendo extrapolada para um "regime" coletivo de uma população considerada em geral. "Esta higiene, como regime de saúde das populações, implica por parte da medicina, um determinado número de intervenções autoritárias e de medidas de controle." (FOUCAULT, 1979h, p.111).

Estas medidas autoritárias passaram a ser requeridas pela necessidade de intervenção higienista em espaços como foco privilegiados das doenças: as prisões, os navios, as instalações portuárias, os hospitais gerais onde se encontravam os vagabundos, os mendigos, os inválidos. "Isolam-se, portanto, no sistema urbano, regiões de medicalização de urgência, que devem tornar pontos de aplicação para exercício de um poder médico intensificado.” (FOUCAULT, 1979h, p.112).

Percebe-se então que desde o século XVIII a sociedade é atravessada por uma série de discursos, ações direcionadas aos hábitos, comportamentos, enfim, todas as características que se relacionam com uma noção de promoção de saúde, mas que em certos casos, a medicalização utilizada para fins políticos, ultrapassa barreiras de sujeição sobre determinadas categorias de indivíduos, em especial as crianças e pessoas que são considerados entraves sociais em um viés político-econômico: os anormais (FOUCAULT, 2006).

Rodrigues e Carvalho (2016) discutem sobre a ampliação do campo da prática médica na atualidade, a qual passa a se associar a outros aspectos da vida que não dizem respeito somente às doenças, senão ao que nas práticas medicalizantes se chama de "risco médico". Os autores escrevem também que por meio de uma autoridade do cuidado, a medicina passou a exercer seu poder por funções normalizadoras, tornando- 
Rev. Interd. em Cult. e Soc. (RICS), São Luís, v. 7, n. 2, p. 261- 275, jul./dez. 2021

ISSN eletrônico: 2447-6498

se uma "estratégia de saber-poder com finalidades mais normalizadoras do que clínicas." (RODRIGUES E CARVALHO, 2016, p.709).

Os autores destacam que no que se refere ao poder de normalização, a psiquiatria sempre teve um papel especial quando se tratava de intervir em situações em que a justiça se encontrava em situações paradigmáticas: "os crimes sem razão". Portanto, tratava-se, não só de produzir toda uma argumentação e um saber para explicar uma conduta criminosa, mas como também de demandar instituições parajudiciárias para lidar com os indivíduos criminosos cuja anormalidade não poderia ser absorvida pelo aparelho de justiça penal "comum".

\section{CONCLUSÕES PROVISÓRIAS}

A partir deste breve percurso histórico que demonstra as proveniências de discursos, de organizações, controle e captura dos corpos pelas instituições disciplinares na confluência com as práticas medicalizantes da psiquiatrização da sociedade, Foucault (2006) propõe um olhar crítico sobre os processos que permearam e contribuíram para a compreensão do modo de funcionamento do poder, (neste estudo específico, do poder disciplinar), que como ele afirma, não pode ser considerado apenas por uma via negativa, de repressão ou até mesmo de violência, visto que na relação de assujeitamento, o poder se manifesta ao atravessar sutilmente por hierarquias, vigilâncias, brandas punições, constantes exames, produções de conhecimento que se materializam em suportes documentários configurando campos de saber e apreciações de verdade, as quais dispersas e em disposições de caráter estratégico fazem funcionar todo um horizonte de normalização de práticas de controle micropolíticas, cujo objetivo fundamental é garantir a dominação numa sociedade produtivista e do consumo. A disciplina, no caso, se torna uma estratégia de controle social em nome da defesa da sociedade por meio de procedimentos de normalização da sociedade.

Concluindo, pode-se dizer que a esta nova função que nasceu dentro da sociedade de disciplinar, a polícia médica, a qual passou a ter um papel fundamental na gestão dos corpos, dos espaços e de suas relações foi encontrando cada vez mais campos de atuação política, principalmente o campo das condutas, as normas, e numa relação cada vez maior com o campo judiciário, ou com o campo das políticas normalizadoras, a medicalização vem ultrapassando os limites e as fronteiras de uma 
Rev. Interd. em Cult. e Soc. (RICS), São Luís, v. 7, n. 2, p. 261- 275, jul./dez. 2021 ISSN eletrônico: $2447-6498$

clínica do cuidado, para se estabelecer como uma verdadeira estratégia de gestão dos problemas sociais, entendidos não por suas características histórico-políticas, mas pela demanda de urgência que as toma como anomalias, como supostas impurezas de uma convivência classificada como saudável em um ponto de vista medicalizante dos corpos e do social pela via psiquiátrica e disciplinar.

\section{REFERÊNCIAS}

CANDIOTTO, César. Disciplina e Segurança em Michel Foucault: A Normalização e a Regulação da Delinquência. Psicologia \& Sociedade; 24(n.spe.): 18-24, 2012.

FOUCAULT, Michel. O Nascimento da Medicina Social. In: Microfísica do Poder. Trad. Roberto Machado. Rio de Janeiro: Graal, 1979c.

FOUCAULT, Michel. O Olho do Poder. In: Microfísica do Poder. Trad. Roberto Machado. Rio de Janeiro: Graal, 1979d.

FOUCAULT, Michel. Verdade e Poder. In: Microfísica do Poder. Trad. Roberto Machado. Rio de Janeiro: Graal, 1979e.

FOUCAULT, Michel. Nietzsche, a Genealogia e a História. In: Microfísica do Poder. Trad. Roberto Machado. Rio de Janeiro: Graal, $1979 f$.

FOUCAULT, Michel. Poder-Corpo. In: Microfísica do Poder. Trad. Roberto Machado. Rio de Janeiro: Graal, 1979g.

FOUCAULT, Michel. A Política de Saúde no Século XVIII. In: Microfísica do Poder. Trad. Roberto Machado. Rio de Janeiro: Graal, 1979h.

FOUCAULT, Michel. O Nascimento do Hospital. In: Microfísica do Poder. Trad. Roberto Machado. Rio de Janeiro: Graal, 1979i.

FOUCAULT, Michel. Sobre a Prisão. In: Microfísica do Poder. Trad. Roberto Machado. Rio de Janeiro: Graal, 1979j.

FOUCAULT, Michel. Espaço, Saber e Poder. Skyline, 1982.

FOUCAULT, Michel. Heterotopias: De Espaços Outros. 1984.

FOUCAULT, Michel. O Poder Psiquiátrico. São Paulo. Martins Fontes, 2012.

FOUCAULT, Michel. A Ordem do Discurso. São Paulo. Loyola, 2013.

FOUCAULT, Michel. A Verdades e as Formas Jurídicas. Rio de Janeiro. Nau Editora, 2013. 
Rev. Interd. em Cult. e Soc. (RICS), São Luís, v. 7, n. 2, p. 261- 275, jul./dez. 2021 ISSN eletrônico: $2447-6498$

FOUCAULT, Michel. O Sujeito e o Poder. 1982. In: Michel Foucault: Uma Trajetória Filosófica. Rio de Janeiro. Forense Universitária, 2013.

FOUCAULT, Michel. Vigiar e Punir. Petrópolis. Editora Vozes, 2014. 